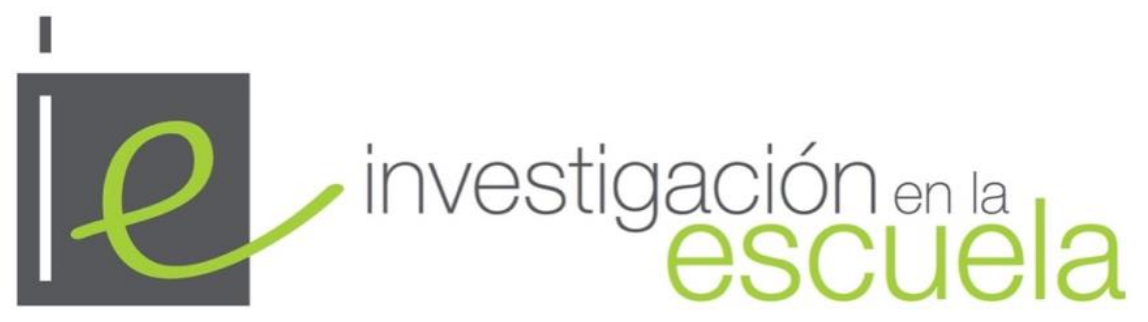

Revista de Investigación e Innovación Educativa nº 104, 2021 | e-ISSN 2443-9991

\title{
Educando las emociones: investigación-acción sobre un programa de educación emocional para el alumnado de educación primaria
}

Training emotions: action-research about emotional education program for primary education students

Gr. Rocío Pérez López es estudiante de Posgrado en la Facultad de Educación, Psicología y Ciencias del Deporte de la Universidad de Huelva (España) · rocio.perez.lope@gmail.com · https://orcid.org/0000-0002-9126-1550

Dra. Inmaculada Gómez Hurtado es Profesora Titular de Universidad en la Facultad de Educación, Psicología y

(iD) Ciencias del Deporte de la Universidad de Huelva (España) · inmaculada.gomez@dedu.uhu.es https://orcid.org/0000-0002-0843-5784

Cómo citar este artículo

Pérez López, R. y Gómez Hurtado, I. (2021). Educando las emociones: investigación-acción sobre un programa de educación emocional para el alumnado de educación primaria. Investigación en la Escuela, 104, 13-28. doi: http://dx.doi.org/10.12795/IE.2021.i104.02

\begin{abstract}
Resumen. Se presenta una investigación acción, realizada con el alumnado de 10 y 11 años. Para ello, se ha puesto en práctica un programa de educación emocional, estructurado en varias fases: diagnóstico, investigación, acción y evaluación. El objetivo principal es diseñar, implementar y valorar una propuesta de educación emocional en un aula, mediante la puesta en práctica de la investigación acción, con el fín de conocer los beneficios en el alumnado. El análisis de los resultados se ha realizado a través de un sistema de categorías organizado en cuatro dimensiones: qué se enseña, cómo, qué disposiciones presentan en relación al programa y desarrollo y conocimiento de las emociones. Como resultado general, la implementación del programa ha favorecido de manera positiva la adquisición de habilidades socioemocionales del alumnado y ha creado un clima óptimo en el aula, reduciendo así la conflictividad. La investigación-acción ha contribuido a la mejora en el proceso de desarrollo del programa y, por tanto, a la consecución de los objetivos. Las principales conclusiones muestran que la investigación-acción es un medio eficaz para poner en práctica programas sociales y emocionales, ya que ayuda a alcanzar sus finalidades fomentando valores humanos, empatía, relaciones positivas, reflexión crítica y ser buenas personas, dejando a un lado actitudes negativas como la competitividad.
\end{abstract}

\begin{abstract}
This article is about an action-research directed towards 10 and 11 years old students. To do it, we have performed an emotional education plan. It will be presented into three different stages: setting and diagnosis, research, action and assessment. The aim is to create, set and assess an emotional education proposal, through action-research, to get benefits in the students. To analyze the results, we have set a categories system organized into four aspects: what do we teach? How do we teach? What kind of willingness are shown towards this plan? And lastly, development and knowledge about emotions. As general results, we can highlight that working on emotional education with children enhances their own socio-emotional abilities. Moreover, this creates a positive atmosphere in the classrooms and reduce conflicts. The main conclusions show that action-research is a good way to put in practice social and emotional education plan, because it helps to get the purposes and it encourages empathy, kindness, critical reflection and development of social relationships. In addition, teaching process should carry out without negative attitudes that promote conflicts and competitions.
\end{abstract}

\section{Palabras clave $\cdot$ Keywords}

Investigación-acción, educación, emoción, personal docente, alumno y enseñanza primaria. Action-research, emotion, education, teaching personnel, pupil and primary education. 


\section{Introducción y estado de la cuestión}

Vivimos en una sociedad repleta de estrés, ansiedad y conflictos, problemas que son una manifestación del analfabetismo emocional (Bisquerra y García, 2018). Marina (2005) propone la educación emocional como solución, resaltando la comprensión y gestión de sentimientos propios y de los demás, la resolución de conflictos, regulación de comportamiento, manejo de la automotivación y el estrés, entre otros aspectos tan importantes para la vida en convivencia. Las escuelas deben tener un papel esencial en este aspecto con el fin de desarrollar estas competencias desde edades tempranas. Sin embargo, el ámbito escolar suele centrarse en la adquisición de conocimientos, dejando a un lado aspectos emocionales, sociales y morales, tan importantes para el desarrollo del alumnado. En esta línea se plantea las siguientes preguntas, siguiendo a Pena et al. (2016): ¿Se forma a los estudiantes en competencias que les serán útiles para un futuro en el ámbito personal y laboral?, ¿se sigue dando importancia a memorizar contenidos y tareas sin hacer ver su aplicación práctica? Las escuelas tienen un papel esencial: criar a un alumnado sano, fomentando no solo su desarrollo cognitivo sino también el social y emocional (Durlak et al., 2011). El éxito personal y profesional de la persona no depende de que tenga las mejores calificaciones, pero sí, en gran medida, de la capacidad de generar emociones positivas en su entorno o de su habilidad para ponerse en el lugar de otra persona (Pena y Extremera, 2015).

\subsection{Inteligencia emocional en educación}

Las teorías de la educación defienden la formación centrada en la adquisición de competencias, habilidades y capacidades (Suberviola, 2020). En este sentido, se encuadra la Inteligencia Emocional, entendida como el conjunto de habilidades para percibir, valorar, expresar, comprender y regular emociones en nosotros mismos y en los demás, así como generar sentimientos que faciliten el pensamiento (Mayer et al., 2016). A pesar de los aspectos tan esenciales a los que hace referencia la inteligencia emocional, algunos autores no están de acuerdo con ese término. McClelland (1973) afirma que el concepto "inteligencia" carece de interés para la educación, ya que es una cualidad innata inmodificable. En su lugar propone "competencia", argumentando su capacidad de modificación mediante entrenamiento, es decir, las personas se pueden volver más competentes. En este sentido, surge el concepto de competencias emocionales, entendidas como el conjunto de conocimientos, capacidades, habilidades y actitudes necesarias para tomar conciencia, comprender, expresar y regular fenómenos emocionales (Bisquerra y García, 2018). Asimismo, se estructuran en cinco bloques explicados en la figura 1.

\section{Figura 1}

Bloques estructurales de las competencias emocionales. Fuente: Bisquerra y García (2018)

\section{Conciencia emocional}

Capacidad para tomar conciencia de las emociones propias y de la de los demás

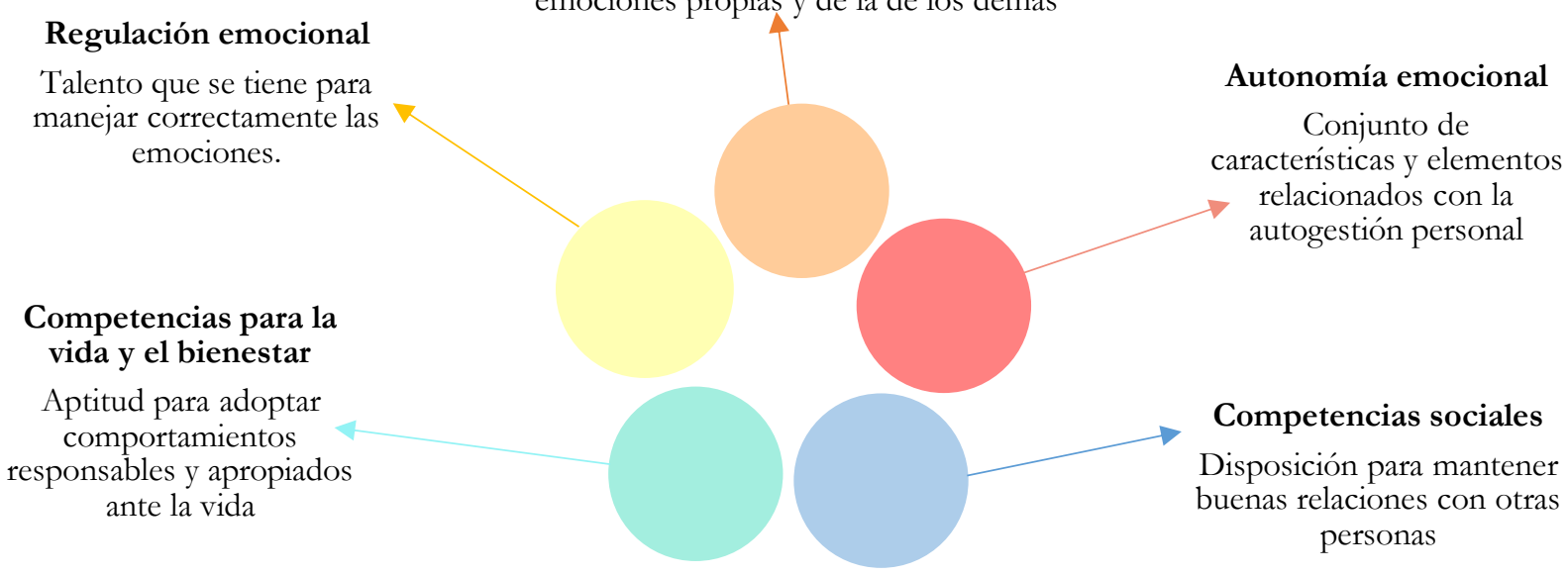

Las emociones se han entendido como algo privado que no deben estar presentes en la vida social y profesional, y, en consecuencia, no están en la educación. Sin embargo, son numerosos los beneficios que tiene trabajar las emociones desde edades tempranas. En este sentido surge la educación emocional, entendida como la adquisición de competencias que se pueden aplicar a multitud de situaciones cotidianas, pretende minimizar la vulnerabilidad de la persona y capacitarle para la vida (Bisquerra et al., 2015). 
Conociendo el concepto, se hace aún más evidente su importancia en las aulas, siendo esencial la implicación de los docentes. De hecho, el profesorado debe dominar sus habilidades emocionales para hacer frente a las diversas situaciones que se les presentan en su día a día (López- Cassá, 2016), como acoger a un escolar que ha perdido a un familiar. En esta línea, los profesores que dominan la inteligencia emocional suelen reducir el impacto emocional negativo en el alumnado y actuar mejor (Pena et al., 2016).

Si se pregunta: ¿recuerdas a todos tus profesores del pasado?, aventurémonos a decir que la respuesta no va a ser sí; y en relación con: ¿cuál fue tu mejor maestro?, seguro que no responden: "fue el que más contenido me enseñaba", más bien resaltan el profesorado por la forma de transmitir, de entender al alumnado, de motivarlos y alentarlos. En esta línea, los docentes son los principales modelos de los escolares, sus creencias acerca de estas habilidades y de la posibilidad de mejora en el alumnado influyen significativamente en la puesta en práctica del programa. De hecho, los docentes que valoran la importancia de estas habilidades emocionales son más propensos a favorecer la educación emocional. Por tanto, para tener escolares emocionalmente inteligentes es necesario formar a los educadores y educadoras y dotarlos de las herramientas necesarias (Pena y Extremera, 2016). En ese sentido, existen numerosos objetivos para tener en cuenta en la formación del profesorado en educación emocional; siguiendo a García (2017) se resalta:

- Sensibilizar al profesorado sobre la importancia de desarrollarse emocionalmente.

- Promover el desarrollo de las competencias emocionales del profesorado.

- Conocer conceptos básicos sobre emociones, educación emocional e inteligencia emocional.

- Ofrecer recursos y procedimientos para la implementación de la educación emocional en el centro.

- Diseñar, preparar y planificar actividades para llevarlas a cabo en las aulas.

- Practicar actividades que permitan desarrollar las competencias emocionales en el profesorado.

- Promover motivación, ilusión, confianza y seguridad en los equipos docentes para que se lleve a cabo la educación emocional en las aulas.

La educación emocional de los docentes contribuye a establecer relaciones afectivas con los estudiantes, a tratar eficazmente los problemas y a crear ambientes idóneos (Brackett et al., 2010). Como se ha indicado anteriormente el rol del profesorado es muy importante, ya que el alumnado aprende por imitación a desarrollar su inteligencia emocional. Los docentes deben favorecer un clima de seguridad, respeto y confianza ante el alumnado con el fin de facilitar la comunicación y establecer relaciones positivas y cordiales. El paso previo es sensibilizarse y formarse en competencias emocionales (López, 2012). Asimismo, cuantas más habilidades emocionales domine el profesorado, más satisfechos suelen estar con su trabajo (Singh y Kumar, 2016).

La puesta en práctica de la educación emocional en el aula tiene que ir acompañada de metodologías que fomenten la participación, la experiencia y el autoanálisis del alumnado. Para ello, se lleva a cabo actividades que permitan la interacción y expresión de sentimientos, emociones y actitudes empáticas, como puede ser la dramatización, el role-playing o el grupo de discusión. Además, la música y el arte tienen un enorme potencial para las vivencias emocionales (Pérez y Filella, 2019).

Sintetizando, en la clase ha de primar el trabajo cooperativo, en equipo y las dinámicas de grupo. El alumnado debe adquirir nuevas habilidades y conocimientos, partiendo de sus propias experiencias y sentimientos, es decir, teniendo un papel activo y siendo los protagonistas del proceso.

\subsection{Investigación-acción}

La necesidad de estudio, formación y mejora constante de los docentes es una realidad y llevar a cabo propuestas de investigación acción es una manera ideal para realizarlo (Faúndez, 2014). Esta, puede definirse como una investigación que enmarca la enseñanza y el aprendizaje como prácticas sociales, donde la reflexión es crucial para identificar posibles problemas. En primer lugar, se analiza las necesidades concretas, se introducen cambios que buscan la mejora y después se examina en qué medida producen beneficios (Banegas \& Consoli, 2020). El profesorado suele ser el protagonista y en ocasiones le acompaña investigadores (Andreis, 2013), no obstante, esto no es necesario, pero sí que las personas participantes estén implicadas con el objeto de estudio (Martinez et al., 2015).

Se busca crear las condiciones adecuadas para que los docentes reflexionen y "a través de enfoques sostenidos, prolongados y colaborativos de la investigación-acción" (Manfra, 2019, p. 185) mejoren sus prácticas educativas. Los agentes tienen que estar dispuestos al cambio y para que este sea significativo y sostenible, debe responder al contexto y a los problemas que pudiese desencadenar estas transformaciones. (Banegas \& Consoli, 2020). Durante el proyecto, se debe tener en cuenta los objetivos que se pretenden conseguir, así como los valores educativos que se persiguen, con el fin de llevar a cabo la consecución de dichos aspectos (Martinez et al., 2015). Asimismo, los estudios sociales demuestran el potencial de la 
indagación para integrarse en la enseñanza y ser una herramienta fundamental que mejore la práctica docente, así como una educación socialmente justa (Manfra, 2019).

En función de los autores se puede observar diferentes formas de organizar las fases de la investigación acción. En este caso, se hace uso de las cuatro etapas recogidas por Oliveira de Vasconcelos y Waldenez de Oliveira (2010):

- De diagnóstico: detectar los problemas de la realidad social específica.

- De investigación: examinar la situación mediante diversos instrumentos de recogida de datos.

- De acción: divulgar los resultados alcanzados, definir los objetivos y las actividades a realizar.

- De evaluación: analizar las posibles mejoras producidas en el transcurso.

Existen diversos instrumentos de recogida de datos, en la investigación se hace uso por un lado de la observación participante. Esta es entendida como una herramienta de recogida, análisis e interpretación de información en la que el investigador tiene un papel activo en las interacciones con el grupo que es objeto de su estudio (Piñero, 2015). Por otro lado, de las notas de campos, con el fin de registrar todo lo que ocurre, ya que ciertas acciones pueden ser vitales en los estudios, siendo el punto de partida para comprender las perspectivas, motivaciones, deseos, justificaciones e interpretaciones de los participantes (Piñero, 2015). Y de entrevistas estandarizadas, es decir, se realiza las mismas preguntas y en orden idéntico a diferentes personas (Labrada, 2016).

La investigación-acción pretende transformar una realidad. "Toda transformación produce un cambio, toda iniciativa de cambio genera nuevo conocimiento sustentado en la investigación, todo nuevo conocimiento puede generar una innovación" (Pérez-Van-Leenden, 2019, p.187).

\section{Método}

La investigación-acción que se presenta va dirigida a una clase con alumnado de 10 y 11 años. El objetivo principal es diseñar, implementar y valorar una propuesta de educación emocional en un aula, mediante la puesta en práctica de la investigación acción, con el fin de conocer los beneficios en el alumnado.

\subsection{Participantes}

El proyecto se lleva a cabo en un aula de $5^{\circ}$ de primaria. La muestra de este estudio está compuesta por 20 escolares, cuatro docentes del centro y la profesora externa, que realiza la investigación acción.

Tabla 2

Muestra del proyecto

\begin{tabular}{|c|c|c|c|c|c|c|}
\hline \multirow[t]{2}{*}{ Participantes } & \multicolumn{2}{|c|}{ Sexo masculino } & \multicolumn{2}{|c|}{ Sexo femenino } & \multicolumn{2}{|c|}{ Total } \\
\hline & N. ${ }^{\circ}$ & $\%$ & $\mathrm{~N}^{\circ}$ & $\%$ & $\mathrm{~N}^{\circ}{ }^{\circ}$ & $\%$ \\
\hline Alumnado & 8 & 32 & 12 & 48 & 20 & 80 \\
\hline Profesorado & 2 & 8 & 2 & 8 & 4 & 16 \\
\hline $\begin{array}{l}\text { Realizadora de la investigación- } \\
\text { acción }\end{array}$ & 0 & 0 & 1 & 4 & 1 & 4 \\
\hline TOTAL & 10 & 40 & 15 & 60 & 25 & 100 \\
\hline
\end{tabular}

\subsection{Diseño de la investigación-acción}

Para llevarla a cabo se ha tenido en cuenta diversas fases, siguiendo a Oliveira de Vasconcelos y Waldenez de Oliveira (2010): contextualización y diagnóstico, investigación, acción y evaluación.

En la fase de contextualización se pretende conocer la realidad concreta del centro, así como los principales problemas existentes. Posteriormente, en la fase de investigación se elaboran los instrumentos y se ponen en práctica para examinar la situación. Seguidamente se elabora y se lleva a cabo un plan de acción, en este caso un programa de educación emocional. Finalmente, se realiza la evaluación de la investigaciónacción donde se pretende conocer los beneficios de la investigación y de la puesta en práctica del proyecto (ver figura 2). 


\section{Figura 2}

Proceso realizado en la investigación acción siguiendo las fases de Oliveira de Vasconcelos y Waldenez de Oliveira (2010)

\section{Contextualización}

\section{Investigación}

\section{Acción}

\section{Evaluación}

Se identifica:

1. Los problemas: falta de afecto, motivación, autocontrol, empatía, desconocimiento emocional y conflictividad.

2. El origen: pobreza extrema, familias con conductas antisociales o consumo de drogas, maltrato y abuso físico $\mathrm{y} / \mathrm{o}$ entornos sociales deprimidos.

1. Se elabora y pone en práctica los instrumentos:

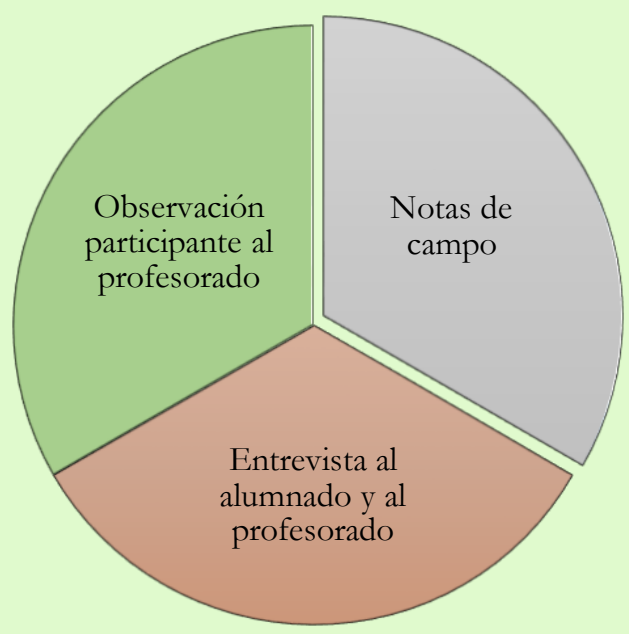

2. Se confecciona un sistema de categorías para el análisis de los datos.

Se elabora y ejecuta el programa "Educando las Emociones"

\begin{tabular}{ll}
\hline Paso 1 & Establecimiento de los objetivos \\
\hline Paso 2 & Planificación y temporalización \\
Paso 3 & Elaboración de las actividades a realizar y los materiales \\
\hline
\end{tabular}

Se analiza los resultados en función de las categorías establecidas anteriormente.

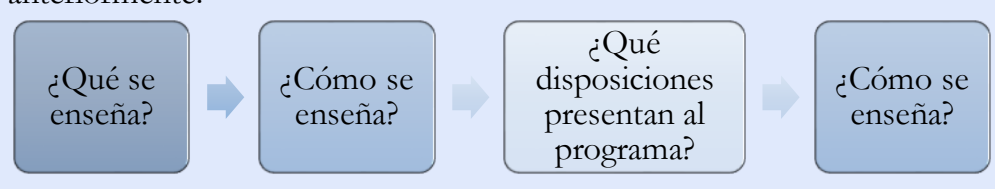




\subsection{Contextualización y diagnóstico}

La intervención e investigación-acción se llevó a cabo en un centro de Educación Primaria, concretamente en el quinto curso. El alumnado es muy diverso teniendo en cuenta el contexto social, cultural, familiar y económico. No obstante, se ha observado unas peculiaridades comunes: falta de afecto, motivación, autocontrol, empatía, desconocimiento emocional y conflictividad. Estos comportamientos parecen estar asociados a una ausencia notable de control de las emociones, un lenguaje carente de comunicación emocional efectiva, ausencia de actitudes empáticas y escasa tolerancia a las frustraciones.

El origen de estas actitudes parece estar relacionado con una serie de factores de riesgo muy variados que escapan del control de los docentes: pobreza extrema, familias con conductas antisociales o consumo de drogas, maltrato y abuso físico y/o entornos sociales deprimidos (Extremera y Fernández Berrocal, 2001). Por ello, se propone un programa de educación emocional con el fin de originar posibles cambios beneficiosos para el alumnado.

\subsection{Fase de investigación}

Los instrumentos que se utilizan son la observación participante por parte del profesorado, llevada a cabo en las sesiones del aula durante la realización del programa de educación emocional. Son los propios investigadores, como docentes colaboradores los que lo ejecutan. Las notas de campos plasmadas por el profesorado partícipe de cada uno de los aspectos relacionados con las categorías de análisis. Y las entrevistas a cuatro docentes y a seis alumnos y alumnas, antes y después de la puesta en práctica del programa. Las entrevistas se nombran como EN (entrevista) seguida del número de entrevista y del minuto en el que se hace esa intervención. Por ejemplo: EN11: al 8' significa entrevista 11 en el minuto 8. Las notas de campo se identifican como OB (observación) seguida del número al que corresponde. Ejemplo: OB.40 hace referencia a la observación número 40 realizada durante la investigación.

Para llevar a cabo el análisis de los datos se usó un sistema de categorías estructurado en cuatro dimensiones y estas a su vez están compuestas por diversas subcategorías. Para la realización del mismo se ha tenido en cuenta el objetivo principal de la investigación y los instrumentos que se han usado, así como la tabla de categoría, utilizada por Cuenca-López et al. (2020, pp. 48-50); se ha llevado a cabo un proceso de "codificación recurrente" (Rodríguez et al., 1996), no siendo ni inductivo ni deductivo. El tratamiento de los datos se utilizó con el programa Atlas Ti, utilizando diferentes códigos para identificar las categorías, subcategorías, indicadores y descriptores. A continuación, se presenta el sistema de categoría que se ha puesto en práctica (ver Tabla 3).

\section{Tabla 3}

Sistema de categorías

\begin{tabular}{|c|c|c|c|}
\hline Categorías & Subcategorías & Indicadores & Descriptores \\
\hline \multirow{9}{*}{$\begin{array}{l}\text { ¿Qué se } \\
\text { enseña? } \\
\text { Contenido }\end{array}$} & \multirow{3}{*}{$\begin{array}{l}\text { Integración de } \\
\text { contenidos }\end{array}$} & $\begin{array}{l}\text { No hay } \\
\text { integración }\end{array}$ & $\begin{array}{l}\text { Predomina un tipo de contenidos (conceptuales, } \\
\text { procedimentales o actitudinales). }\end{array}$ \\
\hline & & $\begin{array}{l}\text { Integración } \\
\text { simple }\end{array}$ & $\begin{array}{l}\text { Se trabaja dos tipos de contenidos relacionados } \\
\text { entre sí. }\end{array}$ \\
\hline & & $\begin{array}{l}\text { Integración } \\
\text { compleja }\end{array}$ & Se interrelacionan los tres tipos de contenidos. \\
\hline & \multirow[t]{2}{*}{ Contextualización } & Realidad del aula & $\begin{array}{l}\text { Se enseña, priorizando en la realidad del aula, } \\
\text { exponiendo ejemplos y situaciones reales de } \\
\text { alumnado y profesorado. }\end{array}$ \\
\hline & & $\begin{array}{c}\text { No se } \\
\text { contextualiza }\end{array}$ & $\begin{array}{l}\text { Se explica los conceptos sin tener en cuenta el } \\
\text { contexto. }\end{array}$ \\
\hline & \multirow{4}{*}{$\begin{array}{l}\text { Dimensiones del } \\
\text { aprendizaje }\end{array}$} & Cognitiva & Centrada en el aprendizaje de conocimiento. \\
\hline & & Emocional & $\begin{array}{l}\text { Toma importancia el interés y la motivación del } \\
\text { alumnado. }\end{array}$ \\
\hline & & Social & $\begin{array}{l}\text { Se centra en las interacciones con su contexto } \\
\text { social concreto. }\end{array}$ \\
\hline & & Socioemocional & $\begin{array}{l}\text { Prima el deseo del alumnado y su motivación, asî } \\
\text { como el contexto y las interacciones de los } \\
\text { mismos. }\end{array}$ \\
\hline
\end{tabular}




\begin{tabular}{|c|c|c|c|}
\hline & \multirow{4}{*}{$\begin{array}{l}\text { Habilidades que se } \\
\text { desarrollan mediante } \\
\text { el programa de } \\
\text { educación } \\
\text { emocional }\end{array}$} & $\begin{array}{l}\text { Percepción, } \\
\text { valoración y } \\
\text { expresión } \\
\text { emocional }\end{array}$ & $\begin{array}{l}\text { Identificar tanto las emociones propias como las } \\
\text { de los demás, fomentándose la empatía y las } \\
\text { relaciones sociales, así como ser capaces de } \\
\text { expresarlas y diferenciarlas. }\end{array}$ \\
\hline & & $\begin{array}{l}\text { Facilitación } \\
\text { emocional }\end{array}$ & $\begin{array}{l}\text { Las emociones se hacen conscientes y se } \\
\text { generan, para facilitar y dirigir la atención hacia } \\
\text { la información importante, beeficiando al } \\
\text { razonamiento, la resolución de problemas, entre } \\
\text { otros. }\end{array}$ \\
\hline & & $\begin{array}{l}\text { Compresión } \\
\text { emocional }\end{array}$ & $\begin{array}{l}\text { Se produce el análisis y el entendimiento de las } \\
\text { emociones, comprendiendo las situaciones que } \\
\text { las producen, así como el paso de un estado } \\
\text { emocional a otro. }\end{array}$ \\
\hline & & $\begin{array}{l}\text { Regulación } \\
\text { emocional }\end{array}$ & $\begin{array}{l}\text { Se desarrolla la capacidad para manejar las } \\
\text { emociones, siendo capaz de utilizar estrategias } \\
\text { para moderarlas, mostrando actitud postiva y } \\
\text { tolerancia a la frustación. }\end{array}$ \\
\hline \multirow{14}{*}{$\begin{array}{l}\text { ¿Cómo se } \\
\text { enseña? } \\
\text { Metodología }\end{array}$} & \multirow{3}{*}{$\begin{array}{l}\text { Relación } \\
\text { profesorado- } \\
\text { alumnado }\end{array}$} & $\begin{array}{l}\text { Comunicación } \\
\text { unidireccional }\end{array}$ & $\begin{array}{l}\text { El profesorado explica y no existe interacción ni } \\
\text { feedback del alumnado. }\end{array}$ \\
\hline & & $\begin{array}{l}\text { Comunicación } \\
\text { bidireccional }\end{array}$ & $\begin{array}{l}\text { El profesorado y el alumnado se intercambian } \\
\text { los papeles de emisor y receptor, participando } \\
\text { como receptor y enviando una retroalimentación } \\
\text { posteriormente, como emisor. }\end{array}$ \\
\hline & & $\begin{array}{l}\text { Comunicación } \\
\text { multidireccional }\end{array}$ & $\begin{array}{l}\text { El profesorado y el alumnado actúan como } \\
\text { emisor y receptor a la misma vez, existiendo una } \\
\text { gran retroalimentación. }\end{array}$ \\
\hline & \multirow[b]{2}{*}{$\begin{array}{l}\text { Papel del } \\
\text { profesorado }\end{array}$} & Instructivo & $\begin{array}{l}\text { Proporciona conocimiento a los estudiantes sin } \\
\text { tener en cuenta sus motivaciones. }\end{array}$ \\
\hline & & Guía & $\begin{array}{l}\text { Orienta en la adquisición del conocimiento al } \\
\text { alumnado, priorizando sus intereses y dando } \\
\text { importancia a la acción constante de los mismos. }\end{array}$ \\
\hline & \multirow[b]{2}{*}{ Papel del alumnado } & Pasivo & Receptor de contenidos. \\
\hline & & Activo & $\begin{array}{l}\text { Implicado en el proceso enseñanza-aprendizaje, } \\
\text { cuestionando, indagando y reflexionando. }\end{array}$ \\
\hline & \multirow{3}{*}{$\begin{array}{l}\text { Tipo de actividades } \\
\text { en función del nivel } \\
\text { de complejidad } \\
\text { cognitiva }\end{array}$} & Baja & $\begin{array}{l}\text { Ejercicios de carácter descriptivo (buscar, copiar } \\
\text { y pegar). }\end{array}$ \\
\hline & & Analítico & Actividades descriptivas y justificativas. \\
\hline & & Sistémico & $\begin{array}{l}\text { Acciones teórico-prácticas descriptivas, } \\
\text { justificativas y argumentativas. }\end{array}$ \\
\hline & \multirow{4}{*}{ Recurse } & $\begin{array}{l}\text { Tradicionales } \\
\text { pasivos }\end{array}$ & $\begin{array}{l}\text { Recursos tradicionales que no implican } \\
\text { participación activa del alumnado. }\end{array}$ \\
\hline & & TICs pasivos & $\begin{array}{l}\text { Recursos TICs que no implican participación } \\
\text { activa del alumnado }\end{array}$ \\
\hline & & $\begin{array}{l}\text { Tradicionales } \\
\text { activos }\end{array}$ & $\begin{array}{l}\text { Recursos tradicionales que implican } \\
\text { participación activa del alumnado }\end{array}$ \\
\hline & & TICs activos & $\begin{array}{l}\text { Recursos TICs que implican participación activa } \\
\text { del alumnado }\end{array}$ \\
\hline \multirow{4}{*}{$\begin{array}{l}\text { ¿Qué } \\
\text { disposiciones } \\
\text { presentan al } \\
\text { programa? } \\
\text { Actitudes }\end{array}$} & \multirow[b]{2}{*}{ Alumnado } & Negativa & $\begin{array}{l}\text { No presentan interés por los contenidos } \\
\text { impartidos. }\end{array}$ \\
\hline & & Positiva & $\begin{array}{l}\text { Los estudiantes están motivados con el } \\
\text { contenido, las actividades propuestas, así como } \\
\text { con los recursos utilizados. }\end{array}$ \\
\hline & \multirow[t]{2}{*}{ Tutor } & Negativa & $\begin{array}{l}\text { No dota a la educación emocional de la } \\
\text { importancia que tiene y su actitud no es positiva } \\
\text { con la aplicación del programa. }\end{array}$ \\
\hline & & Positiva & $\begin{array}{l}\text { Piensa que la inteligencia emocional es } \\
\text { importante y pretende educar a los escolares en }\end{array}$ \\
\hline
\end{tabular}




\begin{tabular}{|c|c|c|c|}
\hline & & & $\begin{array}{l}\text { la misma, con el fin de solucionar las dificultades } \\
\text { apreciadas, así como para capacitarlos para la } \\
\text { vida. }\end{array}$ \\
\hline & \multirow[b]{2}{*}{ Profesorado externo } & Negativa & $\begin{array}{l}\text { No dota a la educación emocional de la } \\
\text { importancia que tiene y su actitud no es positiva } \\
\text { con la aplicación del programa. }\end{array}$ \\
\hline & & Positiva & $\begin{array}{l}\text { Piensa que la inteligencia emocional es } \\
\text { importante y pretende educar al alumnado en la } \\
\text { misma, con el fin de solucionar las dificultades } \\
\text { apreciadas, así como para capacitarlos para la } \\
\text { vida. }\end{array}$ \\
\hline \multirow{10}{*}{$\begin{array}{l}\text { Desarrollo y } \\
\text { conocimiento } \\
\text { de las } \\
\text { emociones }\end{array}$} & & $\begin{array}{l}\text { Contenidos } \\
\text { teóricos }\end{array}$ & $\begin{array}{l}\text { Adquieren los contenidos que se han impartido } \\
\text { en el programa, pero no lo llevan a la práctica. }\end{array}$ \\
\hline & $\begin{array}{l}\text { Conocimiento de } \\
\text { los estudiantes }\end{array}$ & Teórico-práctico & $\begin{array}{l}\text { Obtienen los conocimientos y lo llevan a la } \\
\text { práctica, siendo capaces de conocer las } \\
\text { emociones propias y de los demás, favoreciendo } \\
\text { la empatía y las relaciones, además de promover } \\
\text { actitudes positivas y desarrollar estrategias para } \\
\text { controlar y regular los sentimientos, lo que } \\
\text { favorecerá la tolerancia a la frustración y a la } \\
\text { conflictividad. }\end{array}$ \\
\hline & \multirow{2}{*}{$\begin{array}{l}\text { Actitudes del } \\
\text { alumnado }\end{array}$} & Negativas & $\begin{array}{l}\text { Negación ante los nuevos conocimientos y su } \\
\text { puesta en práctica. }\end{array}$ \\
\hline & & Positivas & $\begin{array}{l}\text { Pretenden aplicar los contenidos en su vida } \\
\text { diaria. }\end{array}$ \\
\hline & \multirow{3}{*}{$\begin{array}{l}\text { Acciones de los } \\
\text { estudiantes }\end{array}$} & Negativas & $\begin{array}{l}\text { Los actos de los estudiantes son peores después } \\
\text { de la aplicación del programa. }\end{array}$ \\
\hline & & Similares & $\begin{array}{l}\text { Las obras de los escolares son equivalentes a las } \\
\text { de antes de la puesta en práctica del programa. }\end{array}$ \\
\hline & & Mejoradas & $\begin{array}{l}\text { Los hechos de los estudiantes han mejorado } \\
\text { considerablemente, poniendo en práctica la } \\
\text { enseñanza de la inteligencia emocional. }\end{array}$ \\
\hline & \multirow{3}{*}{$\begin{array}{l}\text { Habilidades } \\
\text { emocionales }\end{array}$} & $\begin{array}{l}\text { Inteligencia } \\
\text { intrapersonal }\end{array}$ & $\begin{array}{l}\text { Destaca la autoconciencia emocional, } \\
\text { asertividad, el respeto por uno mismo, así como } \\
\text { el manejo del estrés y del estado de ánimo, } \\
\text { siendo capaz de controlarse y autorregularse. }\end{array}$ \\
\hline & & $\begin{array}{l}\text { Inteligencia } \\
\text { interpersonal }\end{array}$ & $\begin{array}{l}\text { Percibe, identifica y valora las emociones de los } \\
\text { demás, presentando empatía. Se favorece la } \\
\text { relación interpersonal y la responsabilidad social. }\end{array}$ \\
\hline & & $\begin{array}{l}\text { Adaptación al } \\
\text { entorno }\end{array}$ & $\begin{array}{l}\text { Se lleva a cabo la resolución de problemas, se } \\
\text { contrasta la realidad, además de presentar } \\
\text { adaptación y flexibilidad. }\end{array}$ \\
\hline
\end{tabular}

\subsection{Acción}

Se elabora el programa "Educando las emociones". El objetivo principal es enseñar a los escolares habilidades emocionales, que les permitan enfrentarse a la vida cotidiana, siendo capaces de reconocer emociones en nosotros y en los demás. El conocimiento de las emociones ajenas fomenta las relaciones sociales y la empatía y el conocimiento de las propias favorece el autocontrol y la autorregulación.

Para la realización de la intervención, se ha tenido en cuenta el Modelo Piramidal de la inteligencia emocional de Mayer y Salovey (1997) (ver figura 3). 


\section{Figura 3}

Modelo Piramidal de la inteligencia emocional. Fuente: Mayer y Salovey (1997)

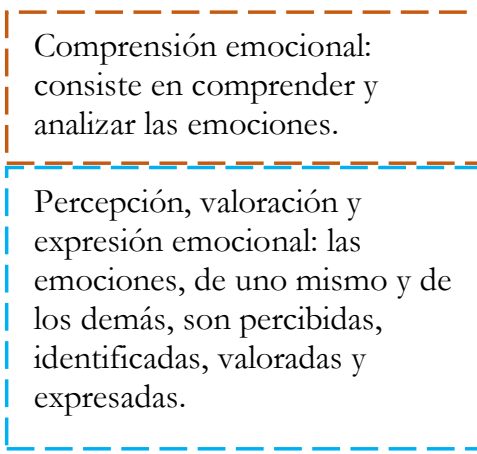

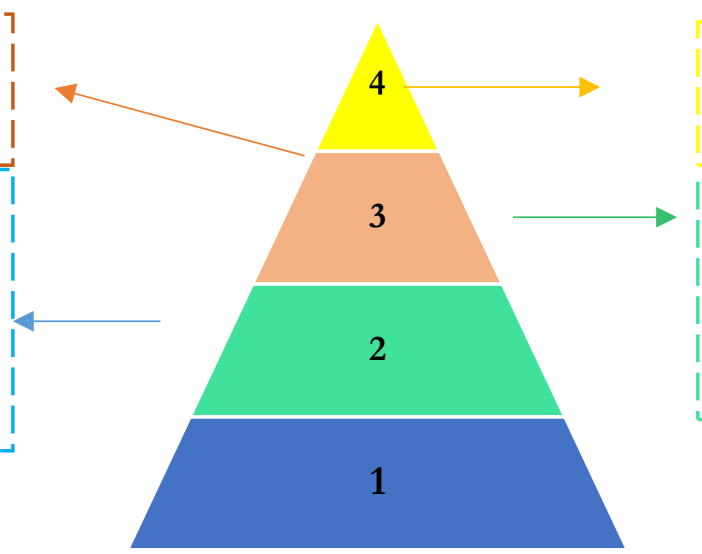

Regulación emocional: capacidad para manejar las emociones.

Facilitación emocional: las emociones se hacen conscientes y dirigen la atención hacia la información importante.

\subsection{Objetivos del programa}

- Ser capaz de identificar emociones propias, ponerles nombre y saber expresarlas.

- Reconocer emociones en los demás, favoreciendo la empatía y las relaciones sociales.

- Comprender las emociones y controlarlas, desarrollando técnicas.

- Incrementar la regulación: generar emociones positivas, tolerancia a la frustración y estrategias de afrontamiento.

\subsection{Planificación y temporalización}

Las actividades han tenido una duración de tres meses y medio, desde el 14 de febrero hasta el 31 de mayo. En la tabla 4 se encuentra la secuencia de las actividades.

Tabla 4

Actividades desarrolladas

\begin{tabular}{|c|c|c|c|c|}
\hline FASES & ACTIVIDAD & Fecha & $\begin{array}{l}\text { TIEMPO } \\
\text { (minutos) }\end{array}$ & DESARROLLO \\
\hline \multirow{3}{*}{ 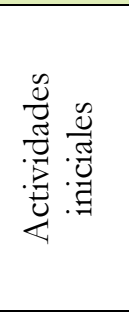 } & Vamos al cine & $14-02$ & 102 & Ver la película del Revés. \\
\hline & $\begin{array}{l}\text { Y tú, ¿qué me } \\
\text { cuentas? }\end{array}$ & $14-02$ & 10 & $\begin{array}{l}\text { Se trabaja en base a una serie de preguntas para } \\
\text { revelar lo que han descubierto, partiendo de } \\
\text { comparaciones de hechos concretos de la película y } \\
\text { de sus propias experiencias. }\end{array}$ \\
\hline & $\begin{array}{c}\text { Escena a } \\
\text { escena }\end{array}$ & $22-02$ & 30 & $\begin{array}{l}\text { Se comparte una serie de escenas de la película, se } \\
\text { analiza qué ocurre y qué emoción expresa. }\end{array}$ \\
\hline \multirow{3}{*}{ 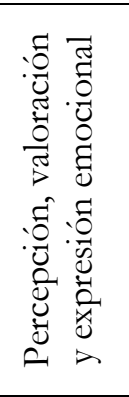 } & $\begin{array}{c}\text { ¿Qué } \\
\text { emociones } \\
\text { conocemos? }\end{array}$ & $01-03$ & 10 & $\begin{array}{l}\text { Se realiza una puesta en común sobre las emociones } \\
\text { que conocían antes y tras la visualización de la } \\
\text { película. }\end{array}$ \\
\hline & $\begin{array}{l}\text { Las paletas } \\
\text { mágicas }\end{array}$ & $01-03$ & 10 & $\begin{array}{l}\text { Se utiliza paletas de madera de colores. A cada color } \\
\text { se le asigna el nombre de una emoción. }\end{array}$ \\
\hline & $\begin{array}{l}\text { El quién es } \\
\text { quién de las } \\
\text { emociones }\end{array}$ & $8-03$ & 30 & $\begin{array}{l}\text { Se divide la clase en dos grupos, A y B. Alguien del } \\
\text { grupo A sale a la pizarra y tiene que expresar una } \\
\text { emoción, mientras que los demás tienen que } \\
\text { adivinarlo. }\end{array}$ \\
\hline 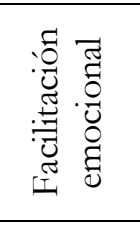 & $\begin{array}{l}\text { Dime cómo te } \\
\text { sientes y te } \\
\text { diré cómo } \\
\text { piensas }\end{array}$ & $15-03$ & 35 & $\begin{array}{l}\text { Se dividen en grupo A: alumnado con emociones } \\
\text { negativas y B: con emociones positivas. El A debe } \\
\text { responder a la pregunta ¿qué sientes al escuchar esta } \\
\text { canción?, mientras escuchan una canción triste, } \\
\text { mientras que el B, escuchando una canción alegre. }\end{array}$ \\
\hline
\end{tabular}




\begin{tabular}{|c|c|c|c|c|}
\hline & $\begin{array}{l}\text { Cada emoción } \\
\text { con su } \\
\text { situación }\end{array}$ & $22-03$ & 25 & $\begin{array}{l}\text { Se divide la clase en grupos de cuatro y se le } \\
\text { proporciona a cada uno una hoja donde aparecen } \\
\text { diferentes situaciones de la vida cotidiana y los } \\
\text { personajes de la película "Del revés". Cada grupo } \\
\text { debe emparejar qué emoción será más útil para } \\
\text { conseguir cada una de las situaciones presentadas. }\end{array}$ \\
\hline & Súper-cuento & $29-03$ & 30 & $\begin{array}{l}\text { Se divide al alumnado en dos grupos en función de } \\
\text { las emociones: A con connotaciones negativas y B } \\
\text { con connotaciones positivas. Cada estudiante tendrá } \\
\text { cuatro palabras, con las cuales formará una historia. }\end{array}$ \\
\hline \multirow{5}{*}{ 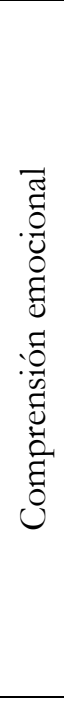 } & $\begin{array}{c}\text { Pasa-palabra } \\
\text { emocional }\end{array}$ & $5-04$ & 45 & $\begin{array}{l}\text { Se forman cuatro equipos que se enfrentan dos a dos. } \\
\text { Deben adivinar la palabra que corresponde con la } \\
\text { definición que se expone. }\end{array}$ \\
\hline & $\begin{array}{c}\text { Tabú } \\
\text { emocional }\end{array}$ & $12-04$ & 35 & $\begin{array}{l}\text { Un estudiante debe intentar que su grupo adivine una } \\
\text { etiqueta emocional sin mencionar las palabras tabúes. }\end{array}$ \\
\hline & $\begin{array}{l}\text { El cuento } \\
\text { emocional }\end{array}$ & $19-04$ & 45 & $\begin{array}{l}\text { Se divide la clase en grupos de cuatro y deben crear } \\
\text { una historia; para ello, lanzan cinco dados: dos con } \\
\text { emociones, uno con lugares, uno con personas y otro } \\
\text { con objetos; anotan lo que les salga y crean en } \\
\text { función de estos ítems. }\end{array}$ \\
\hline & $\begin{array}{l}\text { Tres, dos, } \\
\text { uno... acción }\end{array}$ & $26-04$ & 45 & $\begin{array}{l}\text { Cada grupo representa el cuento que crearon } \\
\text { anteriormente, con la condición de que cada } \\
\text { estudiante adoptará uno de los siguientes papeles: } \\
\text { alegría, negativo, enamorado de la vida y empático. }\end{array}$ \\
\hline & $\begin{array}{l}\text { Reportaje } \\
\text { emotivo }\end{array}$ & $3-05$ & 45 & $\begin{array}{l}\text { Se hace un reportaje fotográfico donde se } \\
\text { representará las emociones aprendidas. }\end{array}$ \\
\hline \multirow{4}{*}{ 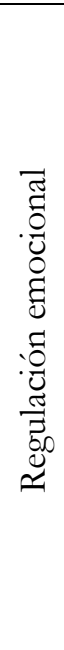 } & $\begin{array}{l}\text { ¿Qué hacemos } \\
\text { cuando nos } \\
\text { sentimos...? }\end{array}$ & $10-05$ & 35 & $\begin{array}{l}\text { Se asigna a cada grupo una emoción (tristeza, alegría, } \\
\text { ira y miedo). Deben pensar situaciones que le han } \\
\text { hecho sentirse así, anotar qué estrategias han } \\
\text { utilizado para sentirse mejor o mantener ese estado } \\
\text { de ánimo y si han sido efectivas o no. }\end{array}$ \\
\hline & $\begin{array}{l}\text { ¿Qué me } \\
\text { hacen sentir? }\end{array}$ & $17-05$ & 45 & $\begin{array}{l}\text { Se forma grupos de cuatro. Uno de cada equipo narra } \\
\text { una experiencia emocional y los otros representan los } \\
\text { roles de: pasota, crítico y escucha activa. }\end{array}$ \\
\hline & $\begin{array}{l}\text { ¡Música y a } \\
\text { pintar! }\end{array}$ & $24-05$ & 45 & $\begin{array}{l}\text { Se eligen varias canciones de diferentes estilos y se } \\
\text { usa un papel continuo blanco para pintar lo que les } \\
\text { transmitan las canciones. }\end{array}$ \\
\hline & $\begin{array}{l}\text { "Las } \\
\text { emociones de } \\
\text { nuestro } \\
\text { cuerpo" }\end{array}$ & $31-05$ & 20 & $\begin{array}{l}\text { Se lleva a cabo una técnica de relajación; para ello, los } \\
\text { escolares se tumban en el suelo y siguen las } \\
\text { indicaciones del profesorado. }\end{array}$ \\
\hline
\end{tabular}

\subsection{Evaluación}

Para el análisis y evaluación de la investigación se utiliza el sistema de categorías expuesto con anterioridad en la tabla 3. A continuación, se presenta, a modo de resumen, los cambios más significativos propuestos (ver tabla 5).

Tabla 5

Cambios propuestos en las diferentes categorías

\begin{tabular}{|c|c|c|c|}
\hline Categorías & Subcategorías & ación & $\begin{array}{c}\text { Propuestas a llevar a cabo durante } \\
\text { el programa }\end{array}$ \\
\hline $\begin{array}{c}\text { ¿Qué se } \\
\text { enseña? } \\
\text { Contenidos }\end{array}$ & $\begin{array}{l}\text { Integración de } \\
\text { contenidos }\end{array}$ & $\begin{array}{lll}\text { Se produce una integración } \\
\text { simple: transmisión de } \\
\text { contenidos conceptuales y en } \\
\text { ocasiones procedimentales. }\end{array}$ & $\begin{array}{lrr}\text { Se dota de gran importancia los } & \text { lot } \\
\text { conocimientos } & \text { actitudinales } \\
\text { emocionales. } & \text { Formando } & \text { una } \\
& & \end{array}$ \\
\hline
\end{tabular}




\begin{tabular}{|c|c|c|c|}
\hline & & & $\begin{array}{l}\text { integración compleja entre los tres } \\
\text { tipos de contenidos. }\end{array}$ \\
\hline & Contextualización & $\begin{array}{l}\text { No se contextualiza los } \\
\text { aprendizajes, sino que se trabaja } \\
\text { con el libro. }\end{array}$ & $\begin{array}{l}\text { Se contextualiza los aprendizajes a la } \\
\text { realidad del aula. }\end{array}$ \\
\hline & $\begin{array}{l}\text { Dimensiones del } \\
\text { aprendizaje }\end{array}$ & Cognitiva & $\begin{array}{l}\text { La dimensión que prima es la } \\
\text { socioemocional. }\end{array}$ \\
\hline & $\begin{array}{l}\text { Conocimientos } \\
\text { que se desarrollan }\end{array}$ & $\begin{array}{l}\text { No se trabajaban ninguna de las } \\
\text { habilidades emocionales. }\end{array}$ & $\begin{array}{l}\text { Se fomenta los cuatro bloques de } \\
\text { habilidades emocionales llevados a la } \\
\text { práctica con la intervención. }\end{array}$ \\
\hline \multirow{5}{*}{$\begin{array}{l}\text { ¿Cómo se } \\
\text { enseña? } \\
\text { Metodología }\end{array}$} & $\begin{array}{l}\text { Relación } \\
\text { profesorado } \\
\text { alumnado }\end{array}$ & $\begin{array}{l}\text { Comunicación unidireccional y } \\
\text { en ocasiones bidireccional. }\end{array}$ & Comunicación multidireccional. \\
\hline & Rol profesorado & Instructivo & Guía \\
\hline & Rol alumnado & Pasivo & Activo \\
\hline & $\begin{array}{l}\text { Actividades en } \\
\text { función del nivel } \\
\text { de complejidad } \\
\text { cognitiva }\end{array}$ & Baja y analítica. & Analítica y sistémica. \\
\hline & Recursos & $\begin{array}{l}\text { Tradicionales pasivos y en pocas } \\
\text { ocasiones TICs pasivas. }\end{array}$ & Tradicionales activos y TICs activos. \\
\hline \multirow{3}{*}{$\begin{array}{l}\text { ¿Qué } \\
\text { disposiciones } \\
\text { presentan al } \\
\text { programa? } \\
\text { Actitudes }\end{array}$} & Alumnado & Actitudes negativas & Actitudes positivas \\
\hline & Tutor/a & $\begin{array}{l}\text { Actitudes negativas y rechazo a } \\
\text { nuevas metodologías y } \\
\text { propuestas de trabajo debido al } \\
\text { desconocimiento. }\end{array}$ & $\begin{array}{l}\text { Actitudes positivas e interés por la } \\
\text { educación emocional del alumnado. }\end{array}$ \\
\hline & $\begin{array}{l}\text { Profesorado } \\
\text { especialista }\end{array}$ & $\begin{array}{l}\text { Actitudes negativas y rechazo a } \\
\text { nuevas metodologías y } \\
\text { propuestas de trabajo debido al } \\
\text { desconocimiento. }\end{array}$ & $\begin{array}{l}\text { Actitudes positivas e interés por la } \\
\text { educación emocional de los } \\
\text { estudiantes. }\end{array}$ \\
\hline \multirow{4}{*}{$\begin{array}{l}\text { Desarrollo y } \\
\text { conocimiento } \\
\text { de las } \\
\text { emociones }\end{array}$} & $\begin{array}{l}\text { Conocimiento del } \\
\text { alumnado }\end{array}$ & $\begin{array}{l}\text { Desconocimiento emocional y } \\
\text { conocimientos teóricos de los } \\
\text { contenidos abordados. }\end{array}$ & $\begin{array}{l}\text { Abordan los conocimientos de forma } \\
\text { teórica- práctica, de tal forma que son } \\
\text { capaces de aplicar los contenidos } \\
\text { aprendidos. Desarrollan y potencian } \\
\text { sus habilidades emocionales. }\end{array}$ \\
\hline & $\begin{array}{l}\text { Actitudes del } \\
\text { alumnado }\end{array}$ & Negativas. & Positivas. \\
\hline & $\begin{array}{l}\text { Acciones de los } \\
\text { estudiantes }\end{array}$ & Violencia y conflictividad. & $\begin{array}{l}\text { Mejoradas: tratan de aplicar lo } \\
\text { aprendido, controlando y regulando } \\
\text { las emociones y mostrándose } \\
\text { empático con los demás. }\end{array}$ \\
\hline & $\begin{array}{l}\text { Habilidades } \\
\text { emocionales }\end{array}$ & $\begin{array}{l}\text { Dificultades en los tres ámbitos: } \\
\text { inteligencia intrapersonal, } \\
\text { inteligencia interpersonal y } \\
\text { adaptación al contexto. }\end{array}$ & $\begin{array}{l}\text { Se muestra mejoras notables en los } \\
\text { tres ámbitos: intrapersonal, } \\
\text { interpersonal y adaptación al } \\
\text { contexto. }\end{array}$ \\
\hline
\end{tabular}

Seguidamente, se analizan los resultados de cada uno de los apartados, siguiendo la tabla de categorías:

¿Qué se enseña?

Para evaluar el desarrollo de las competencias, se valora las habilidades emocionales del alumnado mediante una rúbrica (ver tabla 6). Con el fin de valorar la evolución y la consecución de los objetivos propuestos se realiza una en cada sesión. Seguidamente, se presenta la evolución de los escolares observando la rúbrica inicial y la final, donde se puede apreciar el porcentaje de alumnado y las diferentes valoraciones, en función de cada criterio (ver tablas 7 y 8 ). 
Tabla 6

Rúbrica de evaluación del programa

\begin{tabular}{|c|c|c|c|c|}
\hline \multirow[b]{2}{*}{ Criterios que evaluar en cada sesión } & \multicolumn{4}{|c|}{ ESTÁNDARES } \\
\hline & No supera & $\begin{array}{l}\text { Supera con } \\
\text { dificultad }\end{array}$ & Supera & Destaca \\
\hline $\begin{array}{l}\text { Identificación de emociones y sentimientos } \\
\text { propios }\end{array}$ & $\cdots$ & $\ldots$ & $\cdots$ & $\cdots$ \\
\hline $\begin{array}{l}\text { Reconocimiento de emociones y sentimientos de } \\
\text { los demás }\end{array}$ & $\cdots$ & $\cdots$ & $\cdots$ & $\cdots$ \\
\hline Mejora de las relaciones personales & $\ldots$ & $\ldots$ & $\ldots$ & $\ldots$ \\
\hline Impulsa la comprensión de las emociones & $\ldots$ & $\ldots$ & $\ldots$ & $\ldots$ \\
\hline Estimula el control de los sentimientos & $\ldots$ & $\ldots$ & $\ldots$ & $\ldots$ \\
\hline Fomenta la regulación de las emociones & $\ldots$ & $\ldots$ & $\ldots$ & $\ldots$ \\
\hline
\end{tabular}

Tabla 7

Porcentajes obtenidos en la evaluación inicial, en función de cada criterio

\begin{tabular}{|c|c|c|c|c|c|c|c|c|}
\hline \multirow{3}{*}{ Criterios evaluados } & \multicolumn{8}{|c|}{ EVALUACIÓN INICIAL } \\
\hline & \multicolumn{2}{|c|}{$\begin{array}{l}\text { Alumnado } \\
\text { que no } \\
\text { superan }\end{array}$} & \multicolumn{2}{|c|}{$\begin{array}{c}\text { Alumnado } \\
\text { que superan } \\
\text { con } \\
\text { dificultad }\end{array}$} & \multicolumn{2}{|c|}{$\begin{array}{c}\text { Alumnado } \\
\text { que } \\
\text { superan }\end{array}$} & \multicolumn{2}{|c|}{$\begin{array}{c}\text { Alumnado } \\
\text { que } \\
\text { destacan }\end{array}$} \\
\hline & N. ${ }^{\circ}$ & $\%$ & N. ${ }^{\circ}$ & $\%$ & $\mathrm{~N}^{\circ}{ }^{\circ}$ & $\%$ & N. ${ }^{\circ}$ & $\%$ \\
\hline $\begin{array}{l}\text { Identificación de emociones y sentimientos } \\
\text { propios }\end{array}$ & 14 & 70 & 6 & 30 & 0 & 0 & 0 & 0 \\
\hline $\begin{array}{l}\text { Reconocimiento de emociones y sentimientos } \\
\text { de los demás }\end{array}$ & 18 & 90 & 2 & 10 & 0 & 0 & 0 & 0 \\
\hline Mejora de las relaciones personales & 14 & 70 & 6 & 30 & 0 & 0 & 0 & 0 \\
\hline Estimula la comprensión de las emociones & 16 & 80 & 4 & 20 & 0 & 0 & 0 & 0 \\
\hline Incentiva el control de los sentimientos & 15 & 75 & 5 & 25 & 0 & 0 & 0 & 0 \\
\hline Fomenta la regulación de las emociones & 19 & 95 & 1 & 5 & 0 & 0 & 0 & 0 \\
\hline
\end{tabular}

\section{Tabla 8}

Porcentajes obtenidos en la evaluación final, en función de cada criterio

\begin{tabular}{|c|c|c|c|c|c|c|c|c|}
\hline \multirow{3}{*}{ Criterios evaluados } & \multicolumn{8}{|c|}{ EVALUACIÓN FINAL } \\
\hline & \multicolumn{2}{|c|}{$\begin{array}{l}\text { Alumnado que no } \\
\text { superan }\end{array}$} & \multicolumn{2}{|c|}{$\begin{array}{c}\text { Alumnado } \\
\text { que superan } \\
\text { con } \\
\text { dificultad }\end{array}$} & \multicolumn{2}{|c|}{$\begin{array}{c}\text { Alumnado } \\
\text { que } \\
\text { superan }\end{array}$} & \multicolumn{2}{|c|}{$\begin{array}{c}\text { Alumnado } \\
\text { que } \\
\text { destacan }\end{array}$} \\
\hline & N. ${ }^{\circ}$ & $\%$ & N. ${ }^{\circ}$ & $\%$ & $\mathrm{~N}^{\circ}$ & $\%$ & N. ${ }^{\circ}$ & $\%$ \\
\hline $\begin{array}{l}\text { Identificación de emociones y } \\
\text { sentimientos propios }\end{array}$ & 0 & 0 & 2 & 10 & 14 & 70 & 4 & 20 \\
\hline $\begin{array}{l}\text { Reconocimiento de emociones y } \\
\text { sentimientos de los demás }\end{array}$ & 0 & 0 & 2 & 10 & 15 & 75 & 3 & 15 \\
\hline Mejora de las relaciones personales & 0 & 0 & 2 & 10 & 15 & 75 & 3 & 15 \\
\hline $\begin{array}{c}\text { Estimula la comprensión de las } \\
\text { emociones }\end{array}$ & 0 & 0 & 2 & 10 & 15 & 75 & 3 & 15 \\
\hline $\begin{array}{l}\text { Incentiva el control de los } \\
\text { sentimientos }\end{array}$ & 0 & 0 & 3 & 10 & 15 & 75 & 2 & 15 \\
\hline $\begin{array}{l}\text { Fomenta la regulación de las } \\
\text { emociones }\end{array}$ & 0 & 0 & 4 & 20 & 14 & 70 & 2 & 10 \\
\hline
\end{tabular}


Comparando ambas tablas, se observa mejoras en los aspectos emocionales evaluados. Por tanto, los objetivos específicos se han cumplido, fomentando la consecución del objetivo general: enseñar a los escolares habilidades emocionales, que les permitan enfrentarse a la vida cotidiana, siendo capaces de reconocer emociones en nosotros y en los demás. Cabe señalar que los aspectos más complejos para los estudiantes han sido el autocontrol y la autorregulación emocional.

Asimismo, en la integración de los contenidos se observa una evolución, desarrollando tanto conceptuales como procedimentales y actitudinales. Se contextualiza los aprendizajes con la realidad del aula, sobresaliendo la dimensión socioemocional. En este sentido el alumnado destacaba: "antes solo había peleas" (En11: al 8' (1), "siempre se insultaban" (En13: al 7'), "hemos aprendido a trabajar en equipo" (En13: al 11'), "nos gusta buscar las soluciones de los problemas" (En14: al 15'). Asimismo, destacan diferentes anotaciones, a partir de las cuales se observa el cambio actitudinal de los estudiantes: "maestra tengo ganas de dar la clase de hoy" (OB. 32 (2)), "voy a contar lo que me pasó ayer" (OB.40), entre otras. En cuanto a los conocimientos impartidos cabe resaltar el fomento de las habilidades emocionales.

¿Cómo se enseña?

La comunicación entre profesorado y alumnado ha evolucionado en gran medida hacia la multidireccional. En cuanto a la metodología resalta la activa y participativa, dotando al alumnado de importancia en su proceso de enseñanza- aprendizaje, adquiriendo un rol activo y fomentando un clima de trabajo cooperativo en el aula.

El profesorado toma un rol de guía, alimentando un ambiente de confianza y respeto, mejorando así las relaciones con el alumnado y entre los propios compañeros. Del mismo modo, se ha pasado de la utilización de recursos pasivos a los activos. En este sentido los profesores afirmaban "las actividades son teóricopráctica y es el alumnado el que argumenta y busca soluciones"; de esta forma se promueven actividades con complejidad sistémica. Otro docente destaca: "es mucho más gratificante observar y descubrir las inquietudes y las cuestiones del alumnado que impartir una clase magistral", "los escolares participan mucho". En los estudiantes se observa un gran cambio entre las entrevistas iniciales y las finales: a la pregunta ¿Qué asignaturas te gustan más? un alumno, (En1: al 8’), afirmaba: "solo me gusta educación física, en las otras me aburro, los maestros no paran de hablar". Sin embargo, al terminar el proyecto destacaba: "me gusta mucho las clases de ahora, porque hacemos juegos y cosas nuevas", "nos divertimos mucho" (En11: al 5').

¿Qué disposiciones presentan al programa?

Se caracteriza por la consecución de un clima en el aula positivo, tanto por parte del alumnado, queriendo aprender y aplicar lo aprendido, como del profesorado, dando la importancia que requiere a las emociones en la educación. Antes de la realización del programa el alumnado afirmaba: "hay muchas peleas" (En2: al 4'), "si se mete conmigo le pego" (En3: al 7'), "los maestros no hacen nada" (En5: al 9')," siempre me castigan a mî" (En6: al 8'), y los profesores "los alumnos son muy problemáticos y siempre discuten" (En7: al 7'; En9: al 20'). Es necesario destacar que se observa tensión entre docentes y escolares (OB. 1). Sin embargo, tras la realización del programa, afirmaban: "el clima del aula ha cambiado por completo, todos quieren aprender e intentan que no haya conflictos, no hay comparación con antes" (En8: al 9'). En la misma línea, los estudiantes destacaban "ya hay menos peleas" (En2: al 12'), "maestra yo no le he hecho nada porque tú dices que no tengo que pegar" (En3: al 4"). El clima del aula y del centro es agradable (OB.40).

Desarrollo y conocimiento de las emociones

Anteriormente, se observaba una alta conflictividad en el aula y escasa transmisión de conocimientos y valores. Sin embargo, en este momento, como afirma un docente, "el ambiente es sereno" y prima la participación y el buen clima entre compañeros y profesorado. Se fomenta la adquisición de contenidos y se pone en práctica los valores trabajados en la educación emocional: empatía, relaciones sociales, control y regulación emocional, entre otros. Es decir, se observa mejoras en la inteligencia intrapersonal, inteligencia interpersonal y adaptación al contexto del alumnado. Frases del alumnado: "maestra yo cuento hasta 15 para relajarme", "si estoy muy cabreado me voy para no pegar".

\section{Discusión y conclusiones}

Tras el desarrollo de esta investigación se puede concluir que trabajar la educación emocional con el alumnado favorece la adquisición de habilidades socioemocionales y la creación de un clima positivo en el aula, así como la reducción de la conflictividad y el estrés del alumnado y profesorado.

Es importante conseguir una integración compleja de los contenidos, además de contextualizar los aprendizajes a la realidad del aula. De esta forma, se le da sentido a la enseñanza y se consigue el interés del alumnado. Asimismo, es de vital importancia alfabetizar a los escolares en habilidades emocionales, por lo 
que toma gran relevancia la formación del profesorado. Por otro lado, hay que fomentar metodologías activas que faciliten el trabajo cooperativo y las dinámicas de grupos. Las actividades deben ser participativas y manipulativas y se debe usar materiales innovadores (Pérez y Filella, 2019).

El profesorado adquiere un papel crucial en la formación de los escolares, así como en el ambiente de clase. La autopercepción de los docentes en inteligencia emocional se relaciona directamente con un clima de aula armonioso (Barrientos-Fernández et al., 2020). De hecho, los docentes pueden transmitir sus estados emocionales mediante procesos de contagio emocional (López-Cassà y Pérez-Escoda, 2020). Por ello, es muy importante que estén educados en inteligencia emocional y adquieran estas habilidades (Brackett et al., 2010).

Los programas emocionales favorecen la adquisición de habilidades socioemocionales del alumnado: fomentan la capacidad de percibir, identificar, nombrar y comprender sentimientos propios y de los demás y favorecen las relaciones sociales, permitiendo que puedan desenvolverse en la sociedad (Bisquerra et al., 2015). Es necesario destacar el control y la regulación de las emociones como los objetivos más complicados de adquirir. Por ello, se debe seguir trabajando y hacer hincapié en estos aspectos. No obstante, cabe señalar que se observa una mejora notable en la inteligencia emocional general de los usuarios.

Uno de los puntos más significativos, para un buen desarrollo del proceso de enseñanza y aprendizaje es conocer el estado de ánimo del alumnado. Si están tristes o desmotivados es muy complicado que el proceso educativo sea productivo. Por ello, es importante potenciar la motivación del alumnado, llevando a cabo actividades lúdicas, manipulativas y motivadoras.

Las personas emocionalmente inteligentes suelen ser más optimistas, flexibles y realistas. Además, resuelven sus problemas y afrontan el estrés, sin perder el control (Garaigordobil, 2018). Por tanto, la educación emocional facilita a los estudiantes ciertos recursos y estrategias para enfrentarse a las experiencias de la vida. La educación emocional es preventiva, es importante entrenar las competencias emocionales cuanto antes, para así desarrollarlas y tener un mayor bienestar y calidad de vida (Rueda y Filella, 2016). El aprendizaje de las emociones se trabaja habitualmente de forma transversal, por lo que suele ser insuficiente. Puede ser muy interesante integrarla con todas las materias o incluso tener una asignatura específica. Trabajar las emociones favorece positivamente la educación integral del alumnado, la cual pretende desarrollar todas las dimensiones de la persona, con el fin de llegar al máximo de sus posibilidades (Carmona y Campo, 2018). En esta línea, la forma en que los educadores y estudiantes procesan y responden a las emociones puede mejorar o impedir el desarrollo integral del alumnado (Nathanson et al., 2016).

Asimismo, cabe matizar dos limitaciones principales, en primer lugar, el programa ha durado tres meses y medios. Ha dado muy buenos resultados, pero si no se sigue trabajando estos aspectos con el alumnado podrían interrumpir su aprendizaje e incluso poner en riesgo lo aprendido. Por otro lado, el proyecto está realizado para un aula concreta, sin embargo, es necesario que la comunidad educativa asuma el reto de la formación emocional y que no se trate de iniciativas individuales del profesorado (Pena et al., 2016). La formación en estas habilidades requiere de procesos bien definidos y de programas educativos que cumplan con los criterios de éxito demostrados científicamente (Palomera y Yépez, 2016).

Es importante destacar que las emociones pueden facilitar o dificultar el aprendizaje del alumnado y, por consecuencia, su éxito en la escuela, por lo que hay que atenderlas en el proceso de enseñanza (Zins et al., 2007). Se debe invertir en educación emocional, ya que esto significa interesarse en la calidad educativa. Fomentar estas habilidades es apostar por el desarrollo de competencias que permiten abordar los nuevos retos que plantea la sociedad y dar respuesta a necesidades sociales que con la educación formal no son atendidas adecuadamente (Bisquerra y García, 2018).

Somos seres inteligentes y emocionales (Rueda y Filella, 2016). Desde que tenemos tres años, en nuestro cerebro opera una red de 100 millones de neuronas para juntar ambos procesos. La humanidad lleva muchos años centrándose en el aspecto intelectual y dejando a un lado el emocional. Sin embargo, esto debe cambiar, cobrando la importancia que se merece las emociones. Si la labor docente consistiese en transmitir conocimientos declarativos, hubiésemos sido sustituidos por robots, sin embargo, lo que más nos diferencia de las máquinas es nuestro mundo experiencial y emocional. Las emociones son vehículos integrales de aprendizaje que nos permiten crear lazos con los estudiantes y así desarrollar personas sabias de corazón (Extremera et al., 2016).

Finalmente, cabe resaltar el papel crucial de la investigación-acción en el proceso de enseñanza aprendizaje, permitiendo "sensibilizar, comprender, reflexionar y tomar decisiones para implementar acciones que puedan provocar un cambio positivo en la acción educativa y el contexto" (Martínez et al., 2015, p. 64). Asimismo, contribuye a mejorar la práctica docente, su juicio profesional y responsabilidad fomentando así el papel docente como agentes innovadores en la práctica educativa. 


\section{Referencias}

Andreis, A. (2013). La constitución del profesor: el escribir como investigación sobre su actuación. Investigación en la escuela, 81, 79-90. https://doi.org/10.12795/IE.2013.i81.06

Banegas, D. L., \& Consoli, S. (2020). Action research in language education. In J. McKinley \& H. Rose (Eds.), The Routledge Handbook of Research Methods in Applied Linguistics (pp. 176-187). Routledge.

Barrientos-Fernández, A. et al. (2020). Competencias sociales y emocionales del profesorado de Educación Infantil y su relación con la gestión del clima de aula. Estudios sobre Educación, 38, 59-78. https://doi.org/10.15581/004.38.59-78

Bisquerra, R., Pérez, J.C. y García, E. (2015). Inteligencia emocional en educación. Síntesis, S.A.

Bisquerra, R. y García, E. (2018). La educación emocional requiere formación del profesorado. Participación Educativa: Participación, educación emocional y convivencia, 5(8), 15-27. https://doi.org/10.4438/1886-5097PE

Brackett, M. A., Palomera, R., Mojsa-Kaja, J., Regina, M. \& Salovey, P. (2010). Emotion-regulation ability, burnout, and job satisfaction among British secondary-school teachers. Psychology in the Schools, 47(4), 406-417. https://doi.org/10.1002/pits.20478

Carmona, A. y Campo, L. (2018). Aprendizaje-servicio en la Escuela Solc Nou, una propuesta para la participación y la convivencia. Participación Educativa: Participación, educación emocional y convivencia, 5(8), 15211-2270. https://doi.org/10.4438/1886-5097-PE

Cuenca-López, J. M., Martín, M. y Estepa, J. (2020). Buenas prácticas en educación patrimonial. Análisis de las conexiones entre emociones, territorio y ciudadanía. Aula abierta, 49(1), 45-54. https://doi.org/10.17811/rifie.49.1.2020.45-54

Durlak, J. A., Weissberg, R., Dymnicki, A., Taylor, R. \& Schellinger, K. (2011). The impact of enhancing students' social and emotional learning: A meta-analysis of school-based universal interventions. Child Development, 82(1), 405-432. https://doi.org/10.1111/j.1467-8624.2010.01564.x

Extremera, N. y Fernández-Berrocal, P. (2001). ¿Es la inteligencia emocional un adecuado predictor del rendimiento académico en estudiantes? En P. Disco (Ed.), III Jornadas de Innovación Pedagógica: Inteligencia emocional. Una bríjula para el siglo XXI, CEFASA (pp. 146-157). https://bit.ly/3i7IVC7

Faúndez, J. (2014). Uso de los Mandalas en el Desarrollo Emocional del Profesorado: una experiencia de investigación-acción. Paulo Freire. Revista de Pedagogía Crítica, 16, 149-165. https://doi.org/10.25074/07195532.16.304

Garaigordobil, M. (2018). La educación emocional en la infancia y la adolescencia. Participación Educativa: Participación, educación emocional y convivencia, 5(8), 15-27. https://bit.ly/3rjw6co

García, E. (2017). Formación del profesorado en educación emocional: Diseño, aplicación y evaluación [Tesis doctoral, Universidad de Barcelona]. https://bit.ly/3bvxDpJ

Labrada, R. (2016). La entrevista periodística y la entrevista para la investigación científica. Revista Boletín Redipe, 5(9), 193-199. https://bit.ly/35vLybt

López, È (2012). ¿Cómo educar las emociones? En R. Bisquerra (coord.), La inteligencia emocional en la infancia y la adolescencia (pp. 45-55). Hospital Sant Joan de Déu. https://bit.ly/2XzGij2.

López- Cassá, E. (2016). La educación emocional en la Educación Infantil y Primaria. En J. L. Soler, L. Aparicio, O. Díaz, E. Escolano y A. Rodríguez (Coords.), Inteligencia Emocional y Bienestar II: Reflexiones, experiencias profesionales e investigaciones (557- 570). Ediciones Universidad San Jorge. https://bit.ly/3frgtKi

López-Cassà, È. y Pérez-Escoda, N. (2020). La influencia de las emociones en la educación ante la COVID19: El caso de España desde la percepción del profesorado. Barcelona, Universitat de Barcelona. GROP. Documento electrónico. https://bit.ly/3io40sm

Manfra, M. M. (2019). Action Research and Systematic, Intentional Change in Teaching Practice. Review of Research in Education, 43(1), 163-196. https://doi.org/10.3102/0091732X18821132

Marina, J.A. (2005). Precisiones sobre la Educación Emocional. Revista Interuniversitaria de Formación del profesorado, 19(3), 27-43. https://bit.ly/2K8utwV

Martinez, N. L., Ruiz, E. I., Galindo, R. M. y Galindo, L. (2015). La investigación acción en el trabajo colaborativo colegiado como estrategia para mejorar la práctica docente. Campus Virtuales, 4(1), 56-64. https://bit.ly/2PIFNmm

Mayer, J.D., Caruso, D.R., \& Salovey, P. (2016). The ability model of emotional intelligence: Principles and updates. Emotion Review, 8(4), 290-300. https://doi.org/10.1177\%2F1754073916639667

Mayer, J.D. \& Salovey, P. (1997). "What is emotional intelligence?" En P. Salovey y D. Sluyter (Eds). Emotional Development and Emotional Intelligence: Implications for Educators (pp. 3-31). Basic Books. 
McClelland, D. (1973). Testing for Competence Rather Than for Intelligence. American Psychologist, 28, 1-14. https://bit.ly/2MYMGy8

Nathanson, L. et al. (2016). Creating Emotionally Intelligent Schools With RULER. Emotion review, 8(4), 305-310. https://doi.org/10.1177/1754073916650495

Oliveira de Vasconcelos, V. y Waldenez de Oliveira, M. (2010). Trayectorias de investigación acción: concepciones, objetivos y planteamientos. Revista Iberoamericana de Educación, 53(5). https://doi.org/10.35362/rie5351716

Palomera, R. y Yépez, A. (2016). Educación responsable: un programa para fomentar el desarrollo emocional, social y de la creatividad en toda la comunidad educativa. Padres y Maestros, 368, 24-29. https://bit.ly/2Lh7uk3

Pena, M., Extremera, N. y Rey, L. (2016). Las competencias emocionales: material escolar indispensable en la mochila de la vida. Padres y Maestros, (368), 6-10. https://bit.ly/38HhZpL

Extremera Pacheco, N., Rey Peña, L., \& Pena Garrido, M. (2016). Educadores de corazón. Inteligencia emocional como elemento clave en la labor docente. Padres Y Maestros, (368), 65-72. https://doi.org/10.14422/pym.i368.y2016.011

Pena, M. y Extremera, N. (2016). Inteligencia emocional y educación. Padres Y Maestros, (368), 5. https://bit.ly/2UXgVJV

Pena, M. y Extremera, N. (2015). Competencias emocionales y empleabilidad. En V. Hernández-Franco (Coord.), ¿Cómo orientar profesionalmente a tu bijo?: Manual práctico para padres (pp. 172-183). Fundación Bertelsmann. https://bit.ly/38DJ0Kx

Pérez-Van-Leenden, M. J. (2019). La investigación acción en la práctica docente. Un análisis bibliométrico (2003-2017). Magis, Revista Internacional de Investigación en Educación, 12(24), 177-192. https://doi.org/10.11144/Javeriana.m12-24.ncev

Pérez, N. y Filella, G. (2019). Educación emocional para el desarrollo de competencias emocionales en niños y adolescentes. Praxis \& Saber, 10(24), 23-44. https://doi.org/10.19053/22160159.v10.n25.2019.8941

Piñero, E. (2015). Observación participante: una introducción. Revista San Gregorio, 1, 123-136. https://bit.ly/2MVOYQb

Rodríguez, G., J. Gil, y J. García (1996). Metodología de la Investigación Cualitativa. Aljibe.

Rueda, P. y Filella, G. (2016). Educación emocional para docentes y familias. Padres y Maestros, 368, 30-35. https://bit.ly/3sld5GH

Singh, B. \& Kumar, A. (2016). Effect of Emotional Intelligence and Gender on Job Satisfaction of Primary School Teacher. European Educational Research Journal, 5(1), 1-9. https://doi.org/10.12973/eu-jer.5.1.1

Suberviola, I. (2020). Aspectos básicos sobre el concepto y puesta en práctica de la coeducación emocional. Foro de Educación, 18(1), 189-207. http://doi.org/10.14516/fde.682

Zins, J. E., Bloodworth, M., Weissberg, R. \& Walberg, H. (2007). The Scientific Base Linking Social and Emotional Learning to School Success. Journal of Educational and Psychological Consultation, 17(2-3), 191210. https://doi.org/10.1080/10474410701413145 